\title{
Growth rates and photon yield of growth in natural populations of a marine macroalga Ulva lactuca
}

\author{
Ole Geertz-Hansen, Kaj Sand-Jensen
}

Freshwater-Biological Laboratory, University of Copenhagen, Helsingørsgade 51, DK-3400 Hillerød, Denmark

\begin{abstract}
We examined the photon yield of growth of free-floating Ulva lactuca $\mathrm{L}$. in a eutrophic Danish estuary by exposing discs in mesh cages to 10,40 , and $100 \%$ of ambient light in shallow water Growth per incident or absorbed photon was much higher at 10 than at $100 \%$ of ambient light. Growth was linearly related to photon flux density in low light and $U$. lactuca adapted to the shade by increasing the chlorophyll concentration and thus the photon absorptance in the tissue. Maximum yields at high temperatures in August-September ranged from 16.0 to $21.7 \mathrm{mmol} \mathrm{C} \mathrm{mol}^{-1}$ incident photon and 40 to $61 \mathrm{mmol} \mathrm{C} \mathrm{mol}{ }^{-1}$ absorbed photon at $10 \%$ of ambient light. These values show that light-limited growth of $U$. lactuca proceeds at the maximum attainable photon yields when in situ temperature and nutrient supply are suitable. Such high photon yields for growth are perhaps common among fast-growing species resembling Ulva.
\end{abstract}

\section{INTRODUCTION}

Growth rate determinations of aquatic microalgae and macrophytes are few and difficult to perform in nature. This is unfortunate, because growth determinations are important for evaluation of many central ecological aspects such as regulation of plant abundance by environmental resources and grazing, and rates and efficiencies of energy and material flow through plant communities.

Photosynthesis per incident and absorbed photon (photon yield) has frequently been determined for microalgae and terrestrial leaves in laboratory experiments under light limitation (e.g. Bjorkman 1981, Geider et al. 1985). However, photon yield of growth has rarely been determined for natural aquatic plant populations (see however Ramus 1990). This property is of utmost importance for the success of an organism in low light and more relevant for examining phenotypic light adaptation and interspecific differences than the more frequent measurements of photosynthetic performance. Growth rates are easy to measure in UIva (Vermaat \& Sand-Jensen 1987) and U. lactuca has a sheet-like thallus with well-defined light absorptance properties (Ramus 1978, Sand-Jensen 1988a).

In this study we examined the natural seasonal variation of Ulva lactuca L. growth rate and photon yield of growth. We compared the maximum photon yield of net growth of $U$. lactuca in the field with reported values in photosynthetic experiments with phytoplankton, terrestrial leaves, and U. lactuca in laboratory culture.

\section{MATERIALS AND METHODS}

We measured growth rates from April to November in the eutrophic Roskilde Fjord, Denmark (Borum 1985). Measurements were made in shallow water $(40$ to $70 \mathrm{~cm}$ ) at 4 locations along the estuary (tidal amplitude $<10 \mathrm{~cm}$ ), but only results from 1 location in the mid-part (Stærgård) are presented here. This location had large shallow sediment flats and had slightly higher growth rates of Ulva lactuca than at the other localities, presumably due to high nutrient release from the sediments. Extensive $\mathrm{N}$ limitation was only observed from late June and through July (GeertzHansen 1989).

Growth rates $\left(\mu_{\mathrm{a}}\right)$ were measured as changes in surface area $(A)$ of Ulva lactuca discs of uniform size. Discs were incubated in mesh cages over $7 \mathrm{~d}$, or longer when $\mu_{\mathrm{a}}$ was small. The $U$. lactuca discs (17 $\mathrm{mm}$ in diameter) were punched from large free-floating specimens with a sharpened perspex tube (Vermaat \& Sand-Jensen 
1987). Twelve discs were placed in every cage. Growth rates $\left(\mu_{a}\right)$ were calculated as

$$
\mu_{\mathrm{a}}=\left(\ln A_{t}-\ln A_{0}\right) t^{-1}
$$

where $A_{0}$ is the initial and $A_{t}$ the final surface area after $t$ days of incubation. U. lactuca discs stayed circular, unless grazed, and $A$ was calculated from 2 diameter measurements perpendicular to each other. Heavily grazed discs were discarded, whereas the diameter of slightly grazed discs was measured in unaffected regions (grazing was usually from the margin). The data presented here were based on 7 to 12 surviving discs. The $95 \% \mathrm{CL}$ ranged from 5.6 to $25.5 \%$ of the mean at ambient light and 4.5 to $39.5 \%$ at $10 \%$ of ambient light.

Incubations were made in cages at approximately 100,40 , and $10 \%$ of ambient light in shallow water. Percentage of surface light reaching the cages at the mean depth of $50 \mathrm{~cm}$ was $64 \pm 8 \%$ ( $\pm \mathrm{SD}, \mathrm{n}=24$ ). Nutrient effects on growth were assessed by placing a plastic vial filled with $\mathrm{Na}_{2} \mathrm{HPO}_{4}$ or $\mathrm{NH}_{4} \mathrm{Cl}$ (about $20 \mathrm{~g}$ vial $^{-1}$ ) in the cages. Nutrients were slowly released through small holes in the vial. We made no attempt to quantify the elevation of nutrient loading by this procedure, and only examples of $\mathrm{N}$-stimulation of growth during certain periods are presented here (see Fig. 2). Phosphate addition did not affect Ulva lactuca growth.

Cages were made of perspex and nylon net $1.5 \mathrm{~mm}$ mesh size) and were fixed to the sediment by coiled stainless steel pegs (Geertz-Hansen 1989). About $70 \%$ of their outer surface (the sides and the bottom) was covered by net, maintaining good exchange with the surrounding water and the sediment. Shading was provided by black neutral density plastic sheets firmly attached to the perspex roof and black mesh gauze replacing the clear nylon net. Cages without shading received 99 to $100 \%$ of ambient light.

Continuous underwater light measurements on location were impossible to perform due to lack of reliable instrumentation that could work without daily supervision. Instead, we obtained measurements of the integrated daily surface photon flux density 1400 to $700 \mathrm{~nm}$ ) from the Hydrotechnical Laboratory $30 \mathrm{~km}$ away, and we measured weekly attenuation in the water column above the cages, and light transmittance through the cages. All in situ light measurements were with a $2 \pi$ photon sensor (Licor 183a). Using a conservative $10 \%$ estimate for daily surface reflection (Wetzel 1983), we calculated the mean incident photon flux density for Ulva lactuca (mol photon $\mathrm{m}^{-2} \mathrm{~d}^{-1} ; 1 \mathrm{~mol}$ photon $=1$ Einstein) during every incubation period. We acknowledge that water attenuation may vary during incubation because of changes in water depth $(<10 \mathrm{~cm})$ and turbidity. Though this will affect the weekly estimates of photon yield of growth, this should not lead to systematic errors (over-or underestimates), and the overall patterns should be correct.

Areal growth rates from Eq. (1) $\left[\mathrm{m}^{2}\right.$ produced $\left(\mathrm{m}^{2}\right.$ of Ulva lactuca surface $)^{-1} \mathrm{~d}^{-1}$ \} were transformed to carbon specific growth rates $\left[\mathrm{mol} \mathrm{C}\right.$ produced $\left(\mathrm{m}^{2}\right.$ of $U$. lactuca surface $)^{-1} \mathrm{~d}^{-1}$ ] by first multiplying $\mu_{a}$ by the mean dry weight density [g dry wt $\left(\mathrm{m}^{2} \text { of } U \text {. lactuca surface }\right)^{-1}$ ] of 10 initial and all $U$. lactuca discs retrieved from each cage after incubation, and then by converting dry weight to carbon. The carbon content of 161 discs was measured on a Perkin Elmer CHN-analyzer and showed a constant value of $26.5 \pm 2.0 \mathrm{mmol} \mathrm{C} \mathrm{g}^{-1}$ dry wt, independent of season and shading level. Dry weight was measured by freeze-drying to allow subsequent chlorophyll analysis.

Carbon-specific growth rates and photon flux density are both expressed on an areal basis and directly comparable. The photon yield of growth was calculated by expressing carbon-specific growth rates relative to incident photons $\left(\alpha_{g}\right.$, mol $\mathrm{C}$ fixed during growth per mol incident photon) and absorbed photons $\left(\phi_{g}\right.$, mol $C$ per mol absorbed photon).

The proportion of incident photons being absorbed by the Ulva lactuca was estimated by measuring the chiorophyll content of all $U$. lactuca discs (Vermatt \& Sand-Jensen 1987), and using the relationship to absorptance previously described (Sand-Jensen 1988a). In this relationship absorptance was calculated as incident minus transmitted light, thus including reflection. Later measurements in an integrating sphere (Frost-Christensen \& Sand-Jensen unpubl.) confirmed that reflection was insignificant and yielded almost the same relationship.

\section{RESULTS AND DISCUSSION}

\section{Chlorophyll content and growth rates}

Chlorophyll content ranged from 1.3 to $15.5 \mu \mathrm{g}$ chlorophyll $\mathrm{cm}^{-2}$ (Fig. 1). Chlorophyll content was usually several-fold higher at 10 relative to $100 \%$ of ambient light, and both $\mathrm{N}$-limitation and sporulation reduced chlorophyll markedly. The highest chlorophyll content was found in April. A strong positive relationship between total $\mathrm{N}$ and chlorophyll content of Ulva lactuca was also observed (Geertz-Hansen 1989).

The relationship of growth rate $\left(\mu_{\mathrm{a}}\right)$ to incident light is shown for several weekly periods in April, August, and early October, in which there was little effect of $\mathrm{N}$ addition and zoospore formation on growth (Fig. 2, upper panel). The maximal growth rate was much faster at high temperature in August (ca $0.3 \mathrm{~d}^{-1}$ ) than at lower temperatures in early October (ca $0.2 \mathrm{~d}^{-1}$ ) and April $\left(0.1 \mathrm{~d}^{-1}\right)$. A comparison of $\mu_{\mathrm{a}}$ at a high light level of 


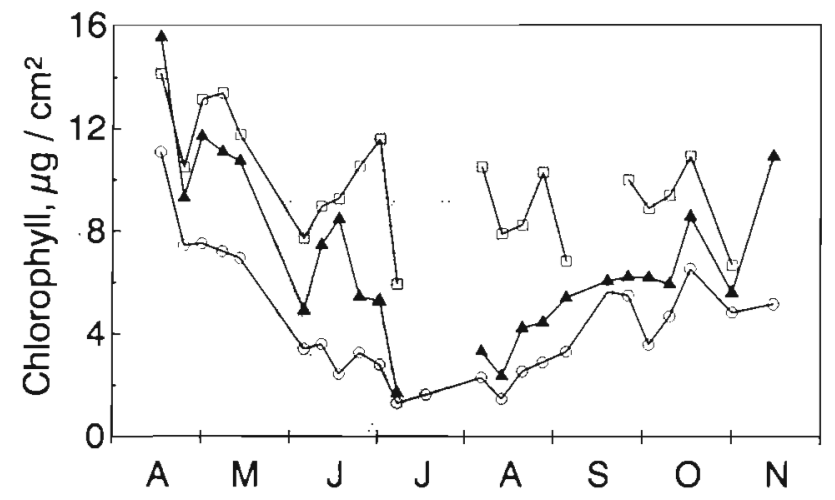

Fig. 1. Ulva lactuca. Seasonal variations of chlorophyll content at (o) $100 \%$, (4) $40 \%$, and (ㄷ) $10 \%$ of ambient light. Shading indicates periods with strong $\mathrm{N}$-limitation and/or sporulation

10 mol photon $\mathrm{m}^{-2} \mathrm{~d}^{-1}$, common for the 3 periods, was consistent with a $Q_{10}$ value for growth of about 2.0. The growth rate was only saturated by ambient light at low temperature $\left(6^{\circ} \mathrm{C}\right)$ in April. The rest of the year, increasing light continued to have a growth enhancing effect in shallow water. Growth rates declined markedly during periods of nutrient limitation and during zoospore formation (Fig. 2, lower panel). Nitrogen addition enhanced growth significantly during these periods.
The rapid growth rates of Ulva lactuca corresponded to previously reported growth rates of subtropical $U$. fasciata in outdoor flow-through tanks (Lapointe \& Tenore 1981). Growth rates of $U$. lactuca exceeded several-fold the reported maximal growth rates of large and structurally complex Fucus and Laminaria species (0.01 to $0.03 \mathrm{~d}^{-1}$; Mann 1972, Guterstam et al. 1978, Nielsen \& Sand-Jensen 1990). The rapid growth rate of Ulva is well explained by its favourable morphology for uptake of nutrient and use of light (i.e. 2-layered thallus, high surface area to volume ratio, all cells photosynthetically active; Rosenberg \& Ramus 1984, Nielsen \& Sand-Jensen 1990).

\section{Photon yield of growth}

Growth per incident photon, $\alpha_{\mathrm{g}}$, varied from 1 to $22 \mathrm{mmol} \mathrm{C}$ (mol incident photon) ${ }^{-1}$, depending on time of year and shading level (Fig. 3). The $\alpha_{\mathrm{g}}$ was high under nutrient saturation and high temperature in August-September and low during nutrient limitation and sporulation (Fig. 3). The $\alpha_{\mathrm{g}}$ was always highest at $10 \%$ of ambient light. At this low light level, the relationship of $\mu_{\mathrm{a}}$ with incident light was linear (Fig. 2) and Ulva lactuca showed the highest chlorophyll content (Fig. 1) and thus the highest light absorptance. At 40
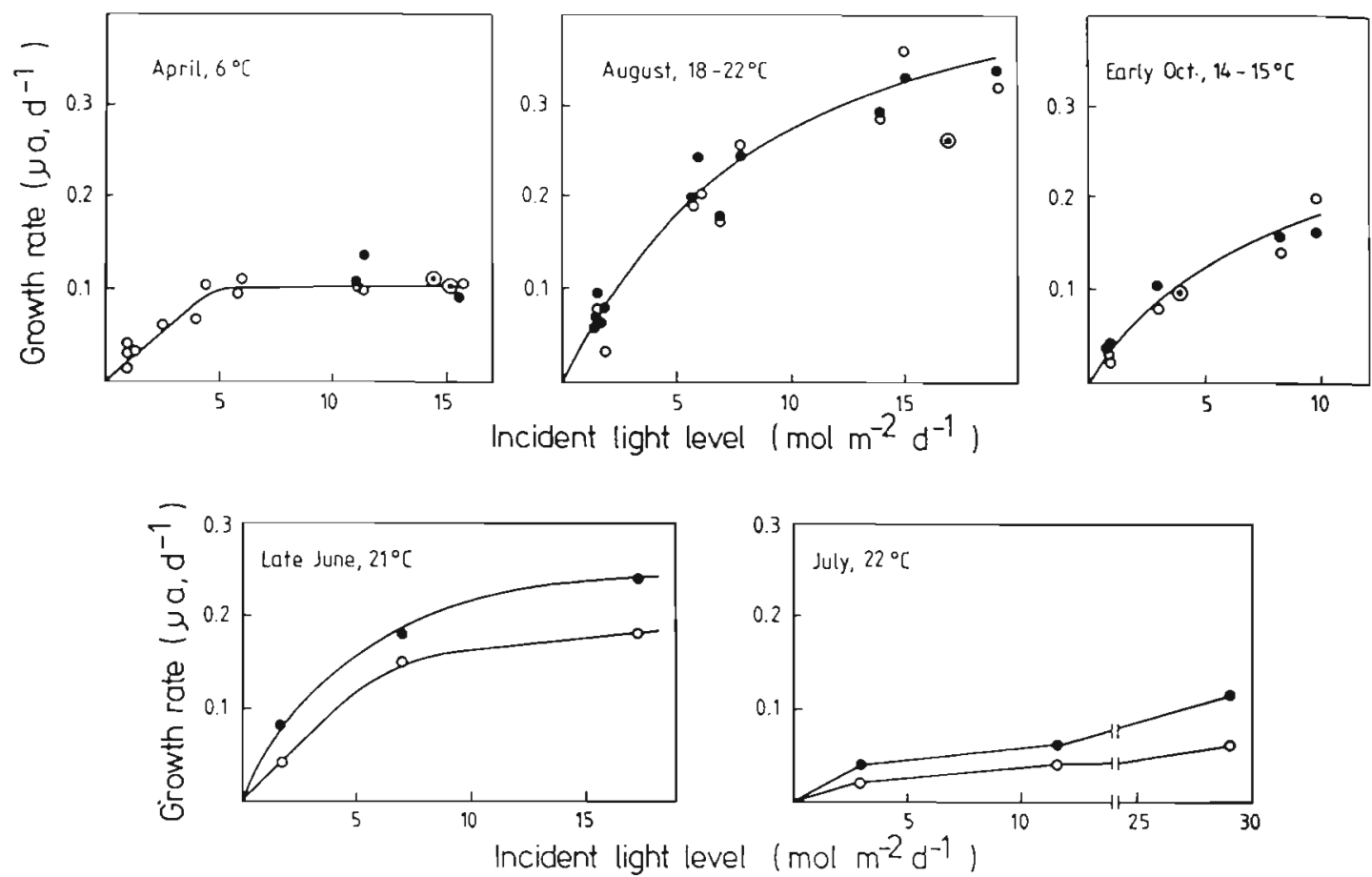

Fig. 2. Ulva lactuca. Growth rates $\left(\mu_{\mathrm{a}}\right)$ as a function of incident photon flux density $(\bullet)$ with or $(0)$ without addition of inorganic N. Upper panel represents 3 periods with no zoospore formation and no effects of $\mathrm{N}$ addition. Lower panel represents 2 periods with strong N-limitation and reduced growth due to sporulation (lower right only). Each point is a mean of 7 to 12 measurements 
and $100 \%$ of ambient light $U$. lactuca is photosaturated for a longer period of the day, and light is consequently not utilized with the maximum efficiency.

Growth per absorbed photon, $\phi_{g}$, ranged from $6 \mathrm{mmol} \mathrm{C}$ (mol absorbed photon) $)^{-1}$ at light saturation in April to a maximum of $61 \mathrm{mmol} \mathrm{C} \mathrm{(mol} \mathrm{absorbed}$ photon $)^{-1}$ at $10 \%$ of ambient light in August (Fig. 3). The $\phi_{\mathrm{g}}$ showed the same overall pattern as $\alpha_{\mathrm{g}}$ except that $\phi$ increased less with reduced light availability because the increased absorptance of shade acclimated Ulva lactuca is corrected for in the calculation of $\phi_{g}$. The $\phi_{g}$ is still markedly higher in incubations at $10 \%$ of ambient light [e.g. 40 to $61 \mathrm{mmol} \mathrm{C}$ (mol absorbed photon $)^{-1}$ in August--September], since growth here is never photosaturated, though we cannot exclude partial saturation during periods of high surface light.

Natural photon yields of Ulva lactuca growth were in the same range as values for $U$. lactuca in laboratory cultures and for terrestrial plant communities under optimum growth conditions. The $\alpha_{\mathrm{g}}$ of well-adapted $U$. lactuca cultures kept at $7^{\circ} \mathrm{C}$ was $12 \mathrm{mmol} \mathrm{C}$ (mol incident photon $)^{-1}$ at $2.14 \mathrm{~mol}$ photon $\mathrm{m}^{-2} \mathrm{~d}^{-1}$ of continuous and constant light and $16 \mathrm{mmol} \mathrm{C}$ (mol incident photon) $)^{-1}$ at $0.76 \mathrm{~mol}$ photon $\mathrm{m}^{-2} \mathrm{~d}^{-1}$ (Table 1 in Sand-

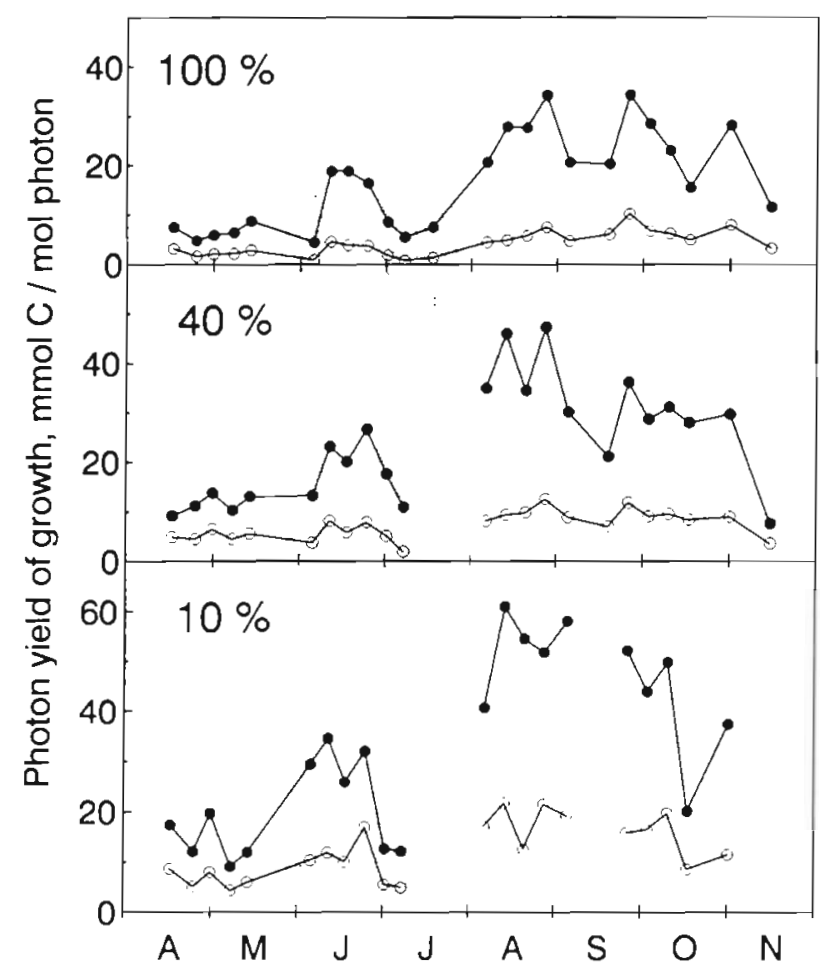

Fig. 3. Ulva lactuca. Seasonal variations of photon yield of growth expressed as (c) growth per incident photon, $\alpha_{g}$ i and $(\bullet)$ growth per absorbed photon, $\phi_{\mathrm{g}}$. Upper panel: $100 \%$ of ambient light; middle panel: $40 \%$ light; lower panel: $10 \%$ light. Shading indicates periods with strong $\mathrm{N}$-limitation and/ or sporulation
Jensen 1988b). Nátural $\alpha_{\mathrm{g}}$ values at comparable light levels of $10 \%$ of the ambient ranged from 4.5 to $21.7 \mathrm{mmol} \mathrm{C}$ (mol incident photon $)^{-1}$ with an overall mean value of $12.3 \mathrm{mmol} \mathrm{C}$ (mol incident photon $)^{-1}$. The maximum $\alpha_{g}$ values at high temperatures in August-September, between 16.5 and $21.7 \mathrm{mmol} \mathrm{C}$ (mol incident photon $)^{-1}$, exceeded the laboratory values for continuous light at $7^{\circ} \mathrm{C}$, even though the natural daily variations in illumination as well as the night period would probably induce higher respiratory costs and make shade adaptation less perfect in the field. These results also suggest a high temperature preference (i.e. ca $20^{\circ} \mathrm{C}$ ) for growth of U. lactuca in the northtemperate Danish waters which is in accordance with previous laboratory measurements (Ho 1975) and the occurrence of $U$. lactuca also within south-temperate and subtropical regions. The preference for high temperatures may reflect the need for higher enzyme concentrations and thus greater maintenance and running costs when Ulva is growing in cold water. A simpler explanation could be that growth rates are limited by rate of enzyme reactions imposed by low temperatures and lack of space to pack more enzymes in. Temperature effects on light saturated growth are well known, but are here expressed under light limitation as well. Unfortunately, it is often forgotten that even though the rate limiting step of photosynthesis under light limitation is a temperature insensitive photochemical process, the subsequent carbon fixation, the production of light harvesting apparatus and the growth process all involve numerous temperature sensitive enzyme reactions.

The $\alpha_{\mathrm{g}}$ and $\phi_{\mathrm{g}}$ values for net growth in the field are not directly comparable to the frequently measured photon yields of light-limited gross photosynthesis, based on incident and absorbed photons, mainly because respiratory costs are included in the former and growth may not have been exclusively lightlimited. The maximum photon yield, $\phi_{\mathrm{m}}$, is $125 \mathrm{mmol}$ $\mathrm{O}_{2}$ produced (mol absorbed photon) $)^{-1}$ based on the $Z$ scheme for photosynthesis (Myers 1980). Assuming a photosynthetic quotient of $1.25 \mathrm{~mol} \mathrm{O} 2$ produced (mol $\mathrm{C}$ fixed $)^{-1}$ we predict a theoretical maximum for gross $\mathrm{C}$ fixation of $100 \mathrm{mmol} \mathrm{C}$ (mol absorbed photon) $)^{-1}$. Photon yields of photosynthesis close to the theoretical maximum have been observed in unicellular algae (Geider et al. 1985), but most values for unicells and terrestrial leaves range from 40 to $80 \mathrm{mmol} \mathrm{C} \mathrm{(mol} \mathrm{absorbed}$ photon) $^{-1}$ (Ehleringer \& Björkman 1977, Bannister \& Weidemann 1984). For conversion of early photosynthates into net growth we have to consider a loss due to costs of synthesis of the different growth products (Penning de Vries et al. 1974) and costs of respiratory maintenance. These costs are variable but probably not less than $40 \%$ (Penning de Vries et al. 1974, Geider \& Osborne 1986). If we include these costs we would 
therefore predict a theoretical maximum photon yield of net growth $\left(\phi_{\mathrm{g}}\right)$ of about $60 \mathrm{mmol} \mathrm{C}$ (mol absorbed photon $)^{-1}$, i.e. $\left.100 \mathrm{mmol} \mathrm{C} \mathrm{(mol} \mathrm{absorbed} \mathrm{photon}\right)^{-1}$ minus $40 \%$ because of respiratory losses. The $\phi_{\mathrm{g}}$ values for net growth of Ulva lactuca in field experiments averaged $33 \pm 17 \mathrm{mmol} \mathrm{C}$ (mol absorbed photon) ${ }^{-1}$ ( $\pm \mathrm{SD}, \mathrm{n}=21$ ) at $10 \%$ of ambient light, which comes as close as possible to light-limited conditions in our experiments. During optimum growth conditions in August-September, $\phi_{\mathrm{g}}$ averaged $53 \pm 7 \mathrm{mmol} \mathrm{C}$ (mol absorbed photon $)^{-1}( \pm S D, n=6)$. We therefore conclude that growth of $U$. lactuca at low light in the field proceeds at efficiencies approaching the maximum possible for conversion of absorbed light energy into new biomass, when temperature and nutrient supply are suitable. This had not been shown previously for aquatic plant populations, but is perhaps of widespread occurrence among fast-growing, opportunistic species resembling Ulva. Obviously, the highest photon yields were attained in $U$. lactuca growing in the most shaded cages, receiving 5 to $7 \%$ of the surface light, and low light is a necessary prerequisite for reaching the highest yields, also in other macroalgae. Nevertheless, relatively high photon yields [mostly 10 to $50 \mathrm{mmol} \mathrm{C}$ (mol absorbed photon $)^{-1}$ ] were even attained by $U$. lactuca in cages receiving about 25 and $60 \%$ of surface light during August-October.

Acknowledgements. We thank B. Dennison, M. Dring, P. Koefoed-Bjornsen, and S. Maberly for comments on the manuscript. This work was partially supported by the Danish Agency for Environmental Protection, The Natural Science Research Council, and The Carlsberg Foundation.

\section{LITERATURE CITED}

Bannister, T T., Weidemann, A. D. (1984). The maximum quantum yield of phytoplankton photosynthesis in situ. J. Plankton Res. 6: 275-294

Bjorkman, O. (1981). Responses to different quantum flux densities. In: Lange, O. L. et al. (eds.) Physiological plant ecology. Encyclopedia of plant physiology, New Series, Vol. 12A. Springer Verlag, Berlin, p. 57-107

Borum, J. (1985). Development of epiphytic communities on eelgrass (Zostera marina) along a nutrient gradient in a Danish estuary. Mar. Biol. 87: 233-241

This article was presented by M. J. Dring, Belfast, Northern Ireland
Ehleringer, J., Björkman, O. (1977). Quantum yields for $\mathrm{CO}_{2}$ uptake in $\mathrm{C}_{3}$ and $\mathrm{C}_{4}$ plants. Plant Physiol. 59: 86-90

Geertz-Hansen, O. (1989). Vækst og omsætning af søsalat (Ulva lactuca) langs en eutrofieringsgradient i Roskilde Fjord. Ph.D. thesis, Univ of Copenhagen

Geider, R. J., Osborne, B. A. (1986). Light absorption, photosynthesis and growth of Nannochloris atomus in nutrientsaturated cultures. Mar Biol. 93: 352-360

Geider, R. J., Osborne, B. A., Raven, J. A. (1985). Light dependence of growth and photosynthesis in Phaeodactylum tricornutum (Bacillariophyceae). J. Phycol. 21: $609-619$

Guterstam, B., Wallentinus, I., Iturriga, I. R. (1978). In situ primary production of Fucus vesiculosus and Cladophora glomerata. Kieler Meeresforsch. Sonderh. 4: 257-266

Ho, Y. (1975). The use of Ulva lactuca L. as an indicator organism for marine pollution. Ph.D. thesis, Univ. of Liverpool

Lapointe, B. E., Tenore, K. R. (1981). Experimental outdoor studies with Ulva fasciata Delile. I: Interactions of light and nitrogen on nutrient uptake, growth and biochemical composition. J. exp. mar. Biol. Ecol. 53: 135-152

Mann, K. H. (1972). Ecological energetics of the seaweed zone in a marine bay on the Atlantic coast of Canada. II. Productivity of seaweeds. Mar. Biol. 14: 199-209

Myers, J. (1980). On the algae: thoughts about physiology and measurements of efficiency. In: Falkowski, P. G. (ed.) Primary productivity in the sea. Plenum Press, New York. p. $1-15$

Nielsen, S., Sand-Jensen, K. (1990). Allometric scaling of maximal photosynthetic growth rate to surface/volume ratio Limnol. Oceanogr. 35: 177-181

Penning de Vries, F. W., Brunsting, A. H. M., van Laar, H. H. (1974). Products, requirements and efficiency of biosynthesis: a quantitative approach. J. theor. Biol. 45: 339-377

Ramus, J. (1978). Seaweed anatomy and photosynthetic performance: the ecological significance of light guides, heterogeneous absorption and multiple scatter. J. Phycol. $14: 352-360$

Ramus, J. (1990). A form-function analysis of photon capture for seaweeds. Hydrobiologia 204/205: 65-71

Rosenberg, G., Ramus, J. (1984). Uptake of inorganic nitrogen and seaweed surface area: volume ratios. Aquat. Bot. 19 : 65-72

Sand-Jensen, K. (1988a). Photosynthetic responses of Uiva lactuca at very low light. Mar. Ecol. Prog. Ser. 50: 195-201

Sand-Jensen, K. (1988b). Minimum light requirements for growth in Ulva lactuca. Mar. Ecol. Prog. Ser. 50: 187-193

Vermaat, J. E., Sand-Jensen, K. (1987). Survival, metabolism and growth of Ulva lactuca L. under winter condations: a laboratory study of bottlenecks in the life cycle. Mar Biol. 95: 55-61

Wetzel, R. G. (1983). Limnology, 2nd edn. Saunders, Philadelphia

Manuscript first received: December 9, 1991

Revised version accepted: February 28, 1992 